\title{
Effect of Cutting Insert Type on Surface Roughness of Hardened AISI 420 Stainless Steel
}

\author{
${ }^{1}$ Anıl Berk Dalkıran, ${ }^{1}$ Furkan Yılmaz, ${ }^{* 1}$ Samet Emre Bilim \\ ${ }^{1}$ Faculty of Engineering, Department of Mechanical Engineering University of Turkish Aeronautical \\ Association, Ankara, Turkey
}

\begin{abstract}
AISI 420 stainless steel is one of the alloys that can be used in various applications due to its malleability, high strength, and weldability. In this study, the effects of cutting parameters (feed rate, depth of cut, and cutting speed) on the surface roughness were investigated during the turning of AISI 420 under dry test conditions using coated carbide and ceramic cutting inserts. Response surface methodology, analysis of variance, and statistical methods of the main effect plot were applied to investigate the effects of input parameters on response values. The results of this study showed that feed rate followed by the depth of cut had the most significant effect on output parameters. According to the experimental data, as the feed rate and depth of cut increase, the surface roughness increases.
\end{abstract}

Key words: AISI 420 stainless steel, Surface roughness, Coated carbide insert, Ceramic insert, Response surface methodology

\section{Introduction}

420 quality stainless steel in the martensitic stainless-steel group determines the limits of its usage areas with its characteristics. In general, the corrosion resistance of 420-grade stainless steel is at standard levels and the tensile strength of 420 -grade stainless steel after heat treatment is high. After heat treatment, the hardness of AISI 420 reaches high levels, and machining materials with high levels of hardness is required hard turning. In this situation, the inserts that should be used for hard turning in these materials (heat-treated or hardened) are carbide, ceramic or cubic boron nitride $(\mathrm{CBN})$.

The chips formed in 420 quality stainless steel, which has a very high machinability level if annealed after manufacturing, are easily broken, and continuous metal chip formation does not happen. It is observed that 420-grade stainless steel reaches a very high surface hardness level after heat treatment. In this respect, knives and similar products are produced with 420 quality stainless steel, which can be reached to an extremely hard and tight form. 420 quality stainless steel, which gains a serious physical resistance against both high pressure and impacts, also provides long-term use. 420 quality stainless steel is used extensively in the machinery industry, food and food production industry, decoration and decorative material production, transportation sector, shafts and pistons, valves, petroleum, and petrochemical fields. Also, kitchen tools can be made with stainless steel of this quality.

Acar et al. [1] investigated the impacts of three cutting parameters, feed rate, cutting speed, and depth of cut on two performance measures, namely surface roughness, and flank wear. The investigation results showed that the most significant parameter on the flank wear was the cutting speed, and the least significant parameter was the feed rate. The surface roughness was mainly affected by the depth of cut. Cutting speed has not exhibited any important impact on the surface roughness. The results show that $\mathrm{Vc}=50 \mathrm{~m} / \mathrm{min}$, ap $=0.1 \mathrm{~mm}$, and $\mathrm{f}=0.05 \mathrm{~mm} / \mathrm{rev}$ 
combination was ideal for the milling of AISI 420 martensitic stainless steel with a hardness of 48 HRC.

Das et al. [2] investigated flank wear, surface roughness, and chip morphology dry hard turning of AISI 4340 steel (49 HRC) using a CVD multilayer coated carbide tool. They used Taguchi's L9, orthogonal array (OA), and analysis of variance (ANOVA) for investigating the effects of feed rate, depth of cut, and cutting speed on the surface roughness, and flank wear of workpiece and tool. Also, they used a scanning electron microscope (SEM) to understand the cutting process, and a cost analysis based on Gilbert's approach the see economic viability. According to the results of this investigation, feed is the most efficient parameter for surface roughness with $70.22 \%$, cutting speed exhibits the highest physical as well as statistical influence on the tool flank wear with $81.93 \%$, and from SEM observation, abrasion was found to be the main wear mechanism of CVD multilayer coated carbide tool.

Kalyon et al. [3] investigated the effects of cutting depth, cutting speed, feed rate, chrome ratio for the surface roughness, and cutting force in hard turning of high chrome cast iron with cubic boron nitride $(\mathrm{CBN})$ insert. They used grey relational analysis based on the Taguchi method and analysis of variance (ANOVA) for observing the effects of surface roughness and cutting speed. According to the result of this investigation, optimal levels of parameters were found cutting speed $100 \mathrm{~m} / \mathrm{min}$, depth of cut $0.1 \mathrm{~mm}$, feed rate $0.05 \mathrm{~mm} / \mathrm{rev}$, and chrome ratio $12 \%$. For the surface roughness, the important parameter was the feed rate. For the resultant force, the significant parameter was the cutting depth.

Palanisamy et al. [4] investigated the machining parameters such as feed rate, nose radius, cutting speed; and machining conditions for AISI 420 stainless steel. Different types of tools have been used for the machining process that depends on nose radius $0.4,0.8$, and 1.2 respectively. According to the results of this investigation, the feed rate of the tool was the most important parameter followed by the cutting speed. Also, the effect of the nose radius of the tool was not effective on hardness.

Ferreira et al. [5] investigated the difference between two different types of ceramic tools during the machining process of AISI H13 steel testing. They used the design of experiments (DOEs) and analysis of variance (ANOVA) to obtain the importance of cutting parameters on the response. According to the results, the most important parameter on the surface roughness is feed rate. Also, the tool geometry has an important impact on the response. The experimental constants decreased as the feed rate increased, correspondingly.

Das et al. [6] investigated the effects of cutting parameters such as feed rate, depth of cut, and cutting speed on surface roughness in turning of 52 HRC hardened AISI 4140 steel with Titanium Nitride PVD coated mixed Al2O3+TiCN ceramic inserts under dry conditions. They used few methods such as orthogonal array (OA), analysis of variance (ANOVA), scanning electron microscope (SEM), and the response surface methodology (RSM). According to the result of this investigation, the feed rate was an important cutting parameter on surface roughness, followed by the cutting speed.

Ashok Kumar Sahoo and Bidyadhar Sahoo [7] investigated surface roughness, flank wear, cutting forces, and chip morphology in finish hard turning of AISI 4340 steel using multilayer $\mathrm{ZrCN}$ and TiN coated carbide and uncoated inserts at a high cutting speed range. The major 
wear mechanisms observed during the machining process are chipping, abrasion, and catastrophic failure. According to the results, the uncoated carbide insert fails due to the chip causing catastrophic failure due to the higher thrust noticed in hard turning in the selected extreme parametric range.

S.Thamizhmanii and S.Hasan [8] investigated hard martensitic AISI $440 \mathrm{C}$ stainless steel and SCM 440 alloy steel and also, CBN and PCBN cutting tools have used the turn these materials. In this investigational study, the running parameters were used such as cutting speed 100, 125, 150,175 , and $200 \mathrm{~m} / \mathrm{min}$ with the feed rate of $0.10,0.20$, and $0.30 \mathrm{~mm} / \mathrm{rev}$ with a constant depth of cut of $1.0 \mathrm{~mm}$ and the length of turning with $150 \mathrm{~mm}$ and $750 \mathrm{~mm}$. As the result of this study, the surface roughness of the stainless steel in terms of value was low at high cutting speed with a low feed rate. The formation of flank wear was low in the PCBN tool than the $\mathrm{CBN}$ tool. High cutting speed and feed rate produced high heat due to less time taken to deform material and increased heat generation.

Zerti et al. [9] investigated the effect of the different machining parameters such as cutting speed, depth of cut, and also feed rate on the surface roughness, cutting force, and cutting power, and therefore the material removal rate during dry hard turning of AISI 420 with 59 HRC. According to the results, the feed rate was the most effective parameter on the surface roughness with a contribution of $80.71 \%$. For the cutting force, the most effective parameter was the depth of cut with a contribution of $65.31 \%$. Also, the depth of cut was the most effective parameter on the cutting power with $37.56 \%$ and the material removal rate with $36.45 \%$. Observed that the ANN and RSM methods work well.

Panda et al. [10] investigated the calculation, modelling, and optimization study of surface roughness in finish dry hard turning of AISI 4340 steel with the coated ceramic the tool has given the cutting speed, axial feed, depth of cut, and nose radius as machining parameters. In this investigation DOEs, RSM, and PSO have been used, for experimentation, assessment, mathematical modelling, and response optimization to analyse the economic viability of the coated ceramic cutting tool insert. According to the results, nose radius was the most important parameter on the surface roughness with $44.59 \%$, followed by the feed rate with $36.82 \%$.

Manivel et al. [11] reported the effect of cutting parameters on the surface roughness and tool wear during hard turning of using ADI. They used the Taguchi orthogonal array method to obtain the right process parameters. Also, they used carbide inserts as cutting tools. They used cutting speed, feed rate, and depth of cut and nose radius parameters during the hard of turning. As a result, they found that the nose radius $(0.8 \mathrm{~mm})$ is the most important cutting parameter for the surface roughness and the nose radius $(0.4 \mathrm{~mm})$ is the most fundamental for tool wear.

Meddour et al. [12] reported the effect of this steel on surface roughness and cutting forces using AISI 52100 Steel (59 HRC) during hard turning. They used cutting speed, depth of cut, feed rate, and tool nose radius. They used the RSM for the modelled of cutting forces and surface roughness and they used the analysis of variance (ANOVA) method for the analysis of input and output parameters. To sum up, they found that the depth of cut is the most important parameter affecting the surface roughness.

Asiltürk et al. [13] presented the attempted to optimize turning parameters based on the Taguchi method to minimize surface roughness. They processed AISI 4140 steel (51 HRC) using an 
orthogonal array on a CNC turning machine. They investigated the effect on surface roughness using the parameters of cutting speed, feed rate, and depth of cut. As a result, they determined the optimum cutting parameters as $120 \mathrm{~m} / \mathrm{min}$ cutting speed, $0.4 \mathrm{~mm}$ depth of cut, and 0.18 $\mathrm{mm} / \mathrm{rev}$ feed rate using analysis of variance (ANOVA).

Bartarya et al. [14] reported the effect of machining parameters on the surface roughness during finish machining of AISI 52100 steel. They tried to measure the effect of cutting speed, feed rate, and depth of cut on cutting force and surface roughness. They observed that depth of cut is the most effective parameter while cutting speed is not effective with the help of analysis of variance (ANOVA).

Das et al. [15] reported the hard turning of AISI 52100 steel using analysis of variance (ANOVA) to determine the effect of cutting parameters (cutting speed, depth of cut, and feed rate) on the cutting force. As a result, the feeding and cutting speed strongly affected the surface roughness, while they found that the cutting depth was the important factor affecting the cutting force and feeding.

Rashid et al. [16] reported their experimental results for hard toning of AISI 4340 (69 HRC) steel using a CBN cutting tool. They have implemented an orthogonal array using the cutting parameter. They applied the Taguchi method to measure the surface roughness of this steel using the parameters of cutting speed, depth of cut, and feed rate. They obtained a machined surface (an average surface roughness value of $45 \mathrm{~nm}$ ) using a CBN cutting tool. As a result, they said, surface roughness increases when the rate of progress is low. They also found that the tool used was over-worn.

Elbah et al. [17] examined the comparison of wiper inserts surface roughness criteria (Ra, Rz, and Rt) with conventional inserts during hard turning of AISI 4140 hardened steel (60 HRC). They used response surface methodology and analysis of variance to determine the parameter affecting surface roughness. They observed that the feed rate and depth of cut have important effects in reducing surface roughness. According to the results, when the wiper ceramic insert CC6050WH and conventional ceramic insert CC6050 are compared, the CC6050WH came to especially in terms of the surface roughness of the workpiece.

Srithar et al. [18] reported the effect of machining parameters on the surface roughness using AISI D2 (64 HRC) using the PCBN tool. They used the orthogonal array method to obtain the optimal process parameters. They used cutting speed, depth of cut, and feed rate as input parameters and surface roughness as an output parameter. As a result, they found that the feed rate is the most important parameter affecting the surface roughness.

Zerti et al. [19] reported the effect of machining parameters on the surface roughness and cutting force of AISI 420 (59 HRC) stainless steel during dry turning. While reporting this experiment, they used Analysis of Variance (ANOVA) and Pareto graphs (Vc, ap, and f). As a result, they determined that the most important factor affecting the surface roughness is the feed rate.

Agrawal et al. [20] reported the conducted 39 sets of hard turning (HT) experimental trials to examine the effect of cutting parameters affecting the roughness of the machined surface. They used CBN insert to hard turning AISI 4340 steel. They used depth of cut, feed rate, and spindle speed as machining parameters. Multiple regression, Random Forest, and Quantile regression 
were used to measure the surface roughness. As a result, they found that random forest regression is the most important model affecting the surface roughness.

As the previous studies examined different investigations that have been performed on the different kinds of steels using various cutting tools. However, the number of studies that compared the effect of the ceramic insert and coated carbide insert on the surface roughness in hard turning of AISI 420 stainless steel is limited. In this study, depth of cut, cutting speed, feed rate, and the type of insert have been chosen as the cutting parameters. While the surface roughness was selected as the response parameter. Taguchi's L18 was employed for the design of experiments (DOEs) and the response surface methodology (RSM) was used to determine the relationship between input parameters and response. The analysis of variance (ANOVA) was performed to find out the most significant parameters that affect surface roughness. The multiple linear regression model was developed to predict the surface roughness based on the input parameters. Finally, the comparison between the experimental and predicted results has been made, and excellent agreement was observed between the results.

\section{Material Method}

\subsection{Material}

In this study was used AISI 420 stainless steel material with a diameter of $50 \mathrm{~mm}$ and a length of $250 \mathrm{~mm}$. Chemical compositions, physical properties, and mechanical properties of AISI 420 stainless steel are given in Table 1, Table 2, and Table 3 respectively.

Table 1. Chemical composition of AISI 420

\begin{tabular}{|c|c|c|c|c|c|c|c|}
\hline $\mathrm{C} \geq$ & $\mathrm{Si} \leq$ & $\mathrm{Mn} \leq$ & $\mathrm{P} \leq$ & $\mathrm{S} \leq$ & $\mathrm{Cr}$ & $\mathrm{Ni} \leq$ & $\mathrm{Mo} \leq$ \\
\hline 0.15 & 1.00 & 1.00 & 0.040 & 0.030 & $12.0-14.0$ & - & - \\
\hline
\end{tabular}

Table 2. Physical properties of AISI 420

\begin{tabular}{|c|c|}
\hline Density, $\mathrm{g} / \mathrm{cm} 3$ & 7.8 \\
\hline Melting Point, ${ }^{\circ} \mathrm{C}$ & $1450-1510$ \\
\hline Specific Heat Capacity, $\mathrm{J} / \mathrm{Kg} \cdot \mathrm{K}$ & 460 at $0-100^{\circ} \mathrm{C}$ \\
\hline Electrical Resistivity, $\mu \Omega \cdot \mathrm{m}$ & 0.55 at $20^{\circ} \mathrm{C}$ \\
\hline Elastic Modulus (Modulus of Elasticity), $\mathrm{GPa}$ & 200 \\
\hline Thermal Conductivity, $\mathrm{W} / \mathrm{m} \cdot \mathrm{K}$ & 24.9 at $100^{\circ} \mathrm{C}$ \\
\hline & 10.3 at $0-100^{\circ} \mathrm{C}$ \\
\hline & 10.8 at $0-315^{\circ} \mathrm{C}$ \\
\cline { 2 - 2 } & 11.7 at $0-538^{\circ} \mathrm{C}$ \\
\hline
\end{tabular}

Table 3. Mechanical properties of AISI 420

\begin{tabular}{|c|c|c|c|c|c|c|}
\hline Condition & $\begin{array}{c}\text { Tensile } \\
\text { Strength, } \\
\mathrm{MPa}, \leq\end{array}$ & $\begin{array}{c}\text { Yield } \\
\text { Strength, } \\
\mathrm{MPa}, \leq\end{array}$ & $\begin{array}{c}\text { Elongation in } \\
50.8 \mathrm{~mm}, \%, \geq\end{array}$ & $\begin{array}{c}\text { Reduction in } \\
\text { Area, \%, },\end{array}$ & Hardness & $\begin{array}{c}\text { Charpy V-notch } \\
\text { Impact Strength, } \\
\mathrm{J}\end{array}$ \\
\hline $\begin{array}{c}\text { Oil quenched } \\
\text { from } 1038^{\circ} \mathrm{C} \\
\text { and tempered at } \\
316^{\circ} \mathrm{C}\end{array}$ & 1724 & 1482 & 8 & 25 & $\begin{array}{c}\sim 52 \mathrm{HRC} \\
\text { Rockwell, } \geq\end{array}$ & $20, \geq$ \\
\hline
\end{tabular}




\subsection{Heat Treatment}

First of all, centre holes were drilled in the upper and lower parts and then taken to the contracted firm for heat treatment. In this process firstly, the material was raised from $0^{\circ} \mathrm{C}$ to $660^{\circ} \mathrm{C}$, and this process was carried out in 2 hours. Then it was raised from $660^{\circ} \mathrm{C}$ to $850^{\circ} \mathrm{C}$, and this process took place in 2 hours. Then, the temperature was increased again from $850^{\circ} \mathrm{C}$ to $1040^{\circ} \mathrm{C}$, and this process was carried out in 2 hours. Heating was done slowly. For the cooling process, the method of cooling with nitrogen in a vacuum was preferred. It was initially started with a pressure of 4.0 bar and this value dropped to 3.8 bar towards the end of the process. The cooling process was carried out in 2 hours. The purpose of performing these processes slowly is not to shock the material, because when the material is shocked, the fragility of the material increases. Finally, the material took its final form by tempering for 2 hours at 200 degrees Celsius. The hardness value obtained after the heat treatment was 50干1 (50.6) HRC.

\subsection{Cutting Parameters}

Cutting parameters of this study are given in Table 4 .

Table 4. Cutting parameters

\begin{tabular}{|c|c|c|c|c|}
\hline \multirow{2}{*}{ Cutting Parameter } & \multirow{2}{*}{ Unit } & \multicolumn{3}{|c|}{ Level } \\
\cline { 3 - 5 } & & 1 & 2 & 3 \\
\hline Depth of cut, $\mathrm{a}_{\mathrm{p}}$ & $\mathrm{mm}$ & 0.2 & 0.3 & 0.5 \\
\hline Cutting speed, $\mathrm{v}_{\mathrm{c}}$ & $\mathrm{m} / \mathrm{min}$ & 150 & 180 & 200 \\
\hline Feed rate, $\mathrm{f}$ & $\mathrm{mm} / \mathrm{rev}$ & 0.05 & 0.08 & 0.12 \\
\hline
\end{tabular}

\subsection{Cutting Tools}

The codes of the tool holders are MWLNR 2525 M08 and DDJNR 2525 M15 respectively, and the brand of the holders is TAKIMSAŞ. Inserts have been supplied suitable for this tool holder. Walter WNMG 060404 and Kennametal DNGA 150404 named tools have been used.
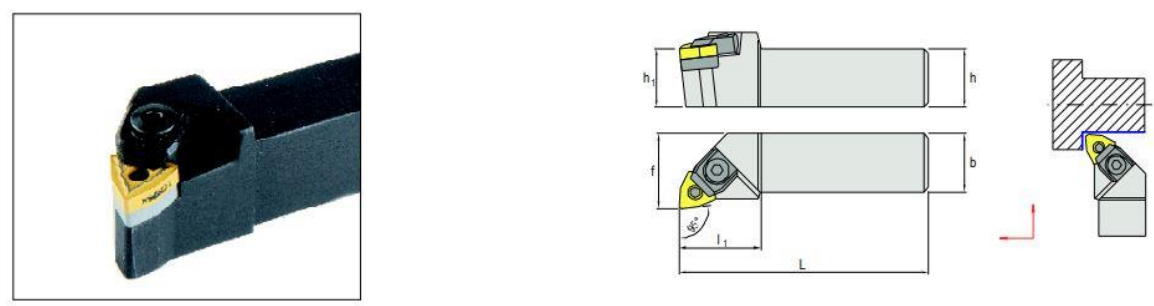

Figure 1. MWLNR 2525 M08
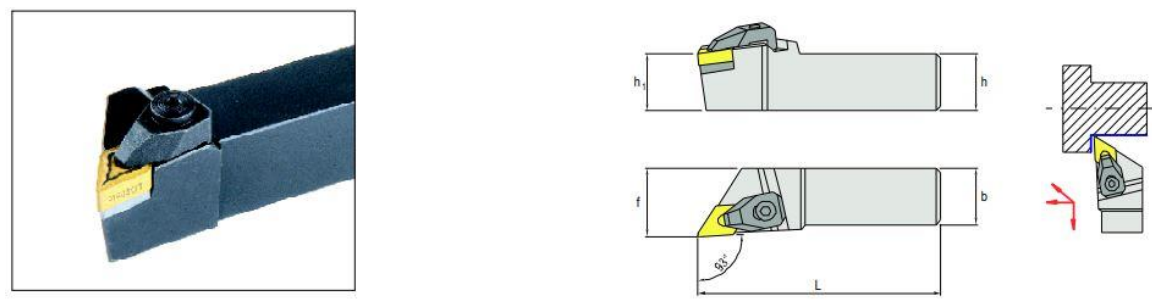

Figure 2. DDJNR 2525 M15 


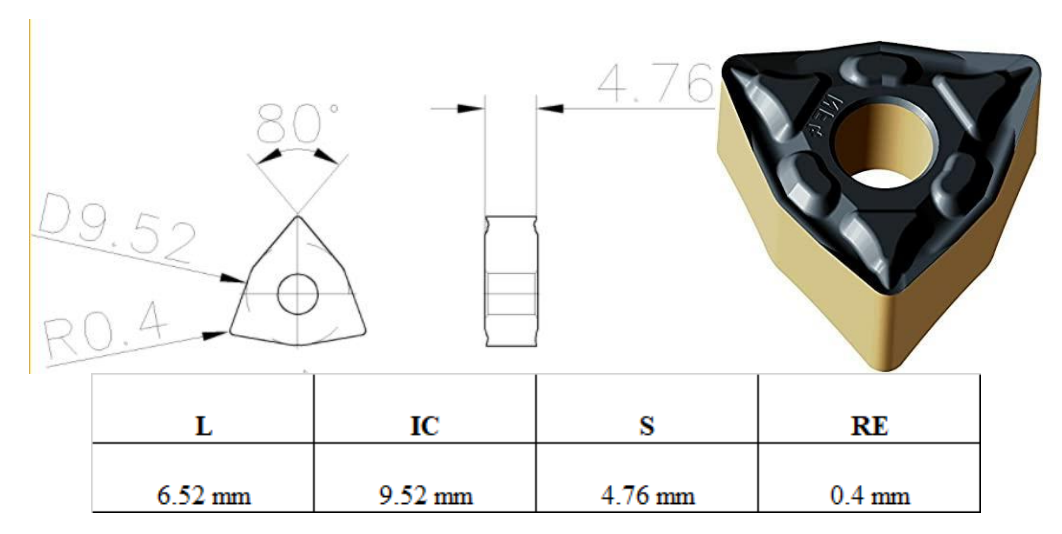

Figure 3. WNMG 060404

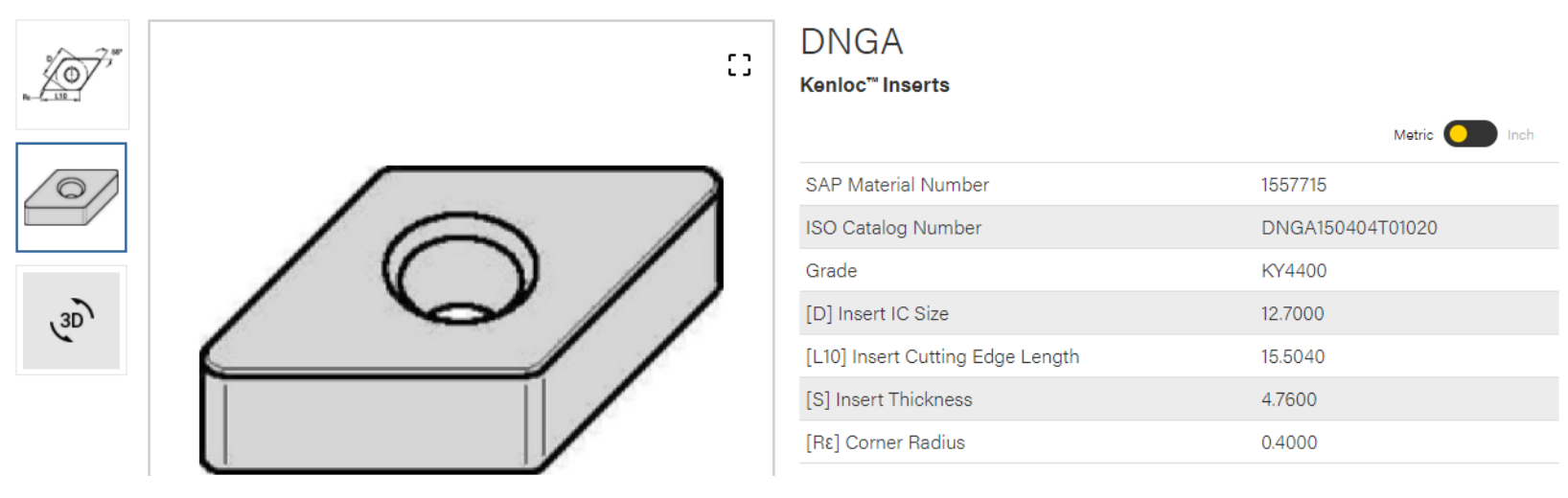

Figure 4. DNGA 150404

\subsection{CNC Machine}

The CNC machine to be used is the Goodway GLS-200 CNC Lathe machine. The technical properties of this machine to be used are specified in Table 5.

Table 5. Technical properties of CNC machine

\begin{tabular}{|c|c|}
\hline \multicolumn{2}{|c|}{ Technical Properties of GLS-200 CNC Machine } \\
\hline Maximum Turning Diameter & $\varnothing 400 \mathrm{~mm}$ \\
\hline Maximum Processing Length & $500 \mathrm{~mm}$ \\
\hline Mirror Size & $8^{\prime \prime}$ \\
\hline Bar Capacity & $\varnothing 52 \mathrm{~mm}$ \\
\hline Spindle Bore Diameter & $\varnothing 66 \mathrm{~mm}$ \\
\hline Spindle Bearing Diameter & $\varnothing 100 \mathrm{~mm}$ \\
\hline Spindle Speed & $4200 \mathrm{rpm}$ \\
\hline
\end{tabular}

\subsection{Surface Roughness Measuring}

Surface roughness measurements were made using a Mitutoyo SJ 410 device with a $0.75 \mathrm{~mm}$ cutting length shown in Figure 5. Measurements were made at the machined locations of the part to measure the surface roughness. The average value of these measurements was accepted as the final surface roughness value. Surface roughness values were measured after the operations were completed. The results for this measurement are shown in Table 6. 


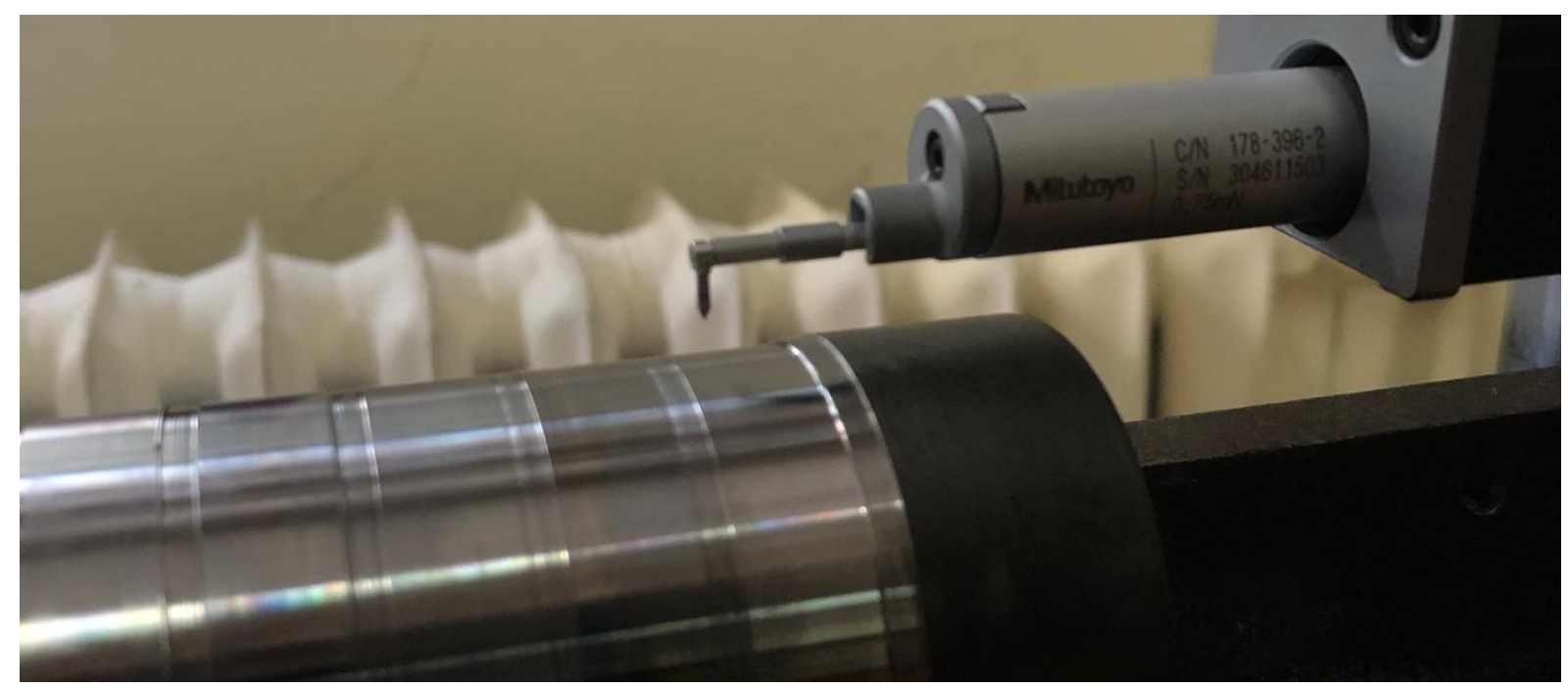

Figure 5. Surface roughness measuring machine, Mitutoyo SJ 410.

Table 6. Experimental results for surface roughness.

\begin{tabular}{|c|c|c|c|c|c|}
\hline Trial & Insert & $\mathbf{a}(\mathrm{mm})$ & $\mathrm{V}(\mathrm{m} / \mathrm{min})$ & f (mm/rev) & $\operatorname{Ra}(\mu \mathrm{m})$ \\
\hline 1 & Carbide & 0.2 & 150 & 0.05 & 0.366 \\
\hline 2 & Carbide & 0.2 & 200 & 0.08 & 0.589 \\
\hline 3 & Carbide & 0.2 & 250 & 0.11 & 0.873 \\
\hline 4 & Carbide & 0.3 & 150 & 0.08 & 0.698 \\
\hline 5 & Carbide & 0.3 & 200 & 0.11 & 1.212 \\
\hline 6 & Carbide & 0.3 & 250 & 0.05 & 0.505 \\
\hline 7 & Carbide & 0.4 & 150 & 0.11 & 1.278 \\
\hline 8 & Carbide & 0.4 & 200 & 0.05 & 0.334 \\
\hline 9 & Carbide & 0.4 & 250 & 0.08 & 0.496 \\
\hline 1 & Ceramic & 0.2 & 150 & 0.05 & 0.275 \\
\hline 2 & Ceramic & 0.2 & 200 & 0.08 & 0.503 \\
\hline 3 & Ceramic & 0.2 & 250 & 0.11 & 0.783 \\
\hline 4 & Ceramic & 0.3 & 150 & 0.08 & 0.594 \\
\hline 5 & Ceramic & 0.3 & 200 & 0.11 & 0.931 \\
\hline 6 & Ceramic & 0.3 & 250 & 0.05 & 0.432 \\
\hline 7 & Ceramic & 0.4 & 150 & 0.11 & 0.974 \\
\hline 8 & Ceramic & 0.4 & 200 & 0.05 & 0.279 \\
\hline 9 & Ceramic & 0.4 & 250 & 0.08 & 0.417 \\
\hline
\end{tabular}

\subsection{Response Surface Methodology (RSM)}

The response surface methodology (RSM) is a technique that is utilized to decide a connection among input and output variables. This technique incorporates six phases:

- determine the input and output variables

- receiving a trial configuration plan

- carrying out a regression investigation utilizing response surface methodology (RSM)

- calculating the analysis of variance for input variables to decide the main boundary which affects the output parameters

- examining the results of the response surface methodology (RSM) and choosing whether the model of RSM needs screening factors or not 
In this examination, the impacts of cutting variables (cutting speed, depth of cut, and feed rate) on the response (surface roughness) were researched under dry cutting conditions. The primary raw was allowed to the depth of cut (a), the second raw to the cutting speed (V) and the third raw to the feed rate (f).

\section{Result and Discussion}

Approximately 51 (50.6) HRC AISI 420 was processed using coated carbide and ceramic inserts. Experimental setup shown in Figure 6. After these procedures, the surface roughness measurements were performed. As a result of the measurements, experimental data were analysed using methods such as RSM, ANOVA, and regression analysis to determine the effect and contribution of the specified cutting parameters.

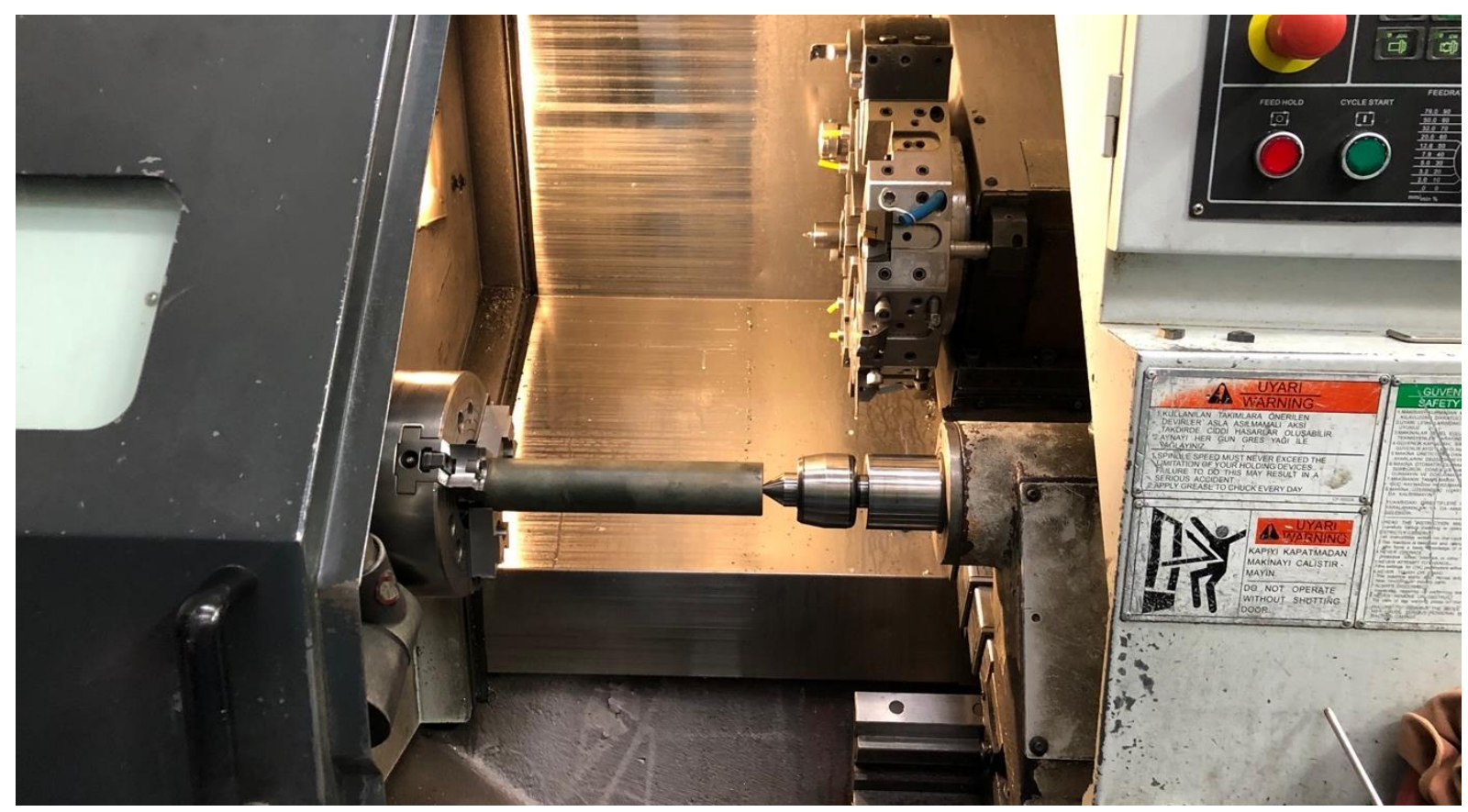

Figure 6. Experimental setup.

The main effect charts are given in Figure 7 and Figure 8 to see the effects of the cutting inserts used on the surface roughness. According to these graphs, the feed rate has been the most effective cutting parameter that affects surface roughness, while the depth of cut and the cutting speed did not have a significant effect. Also, cutting speed has a minimal effect on the output parameters. 


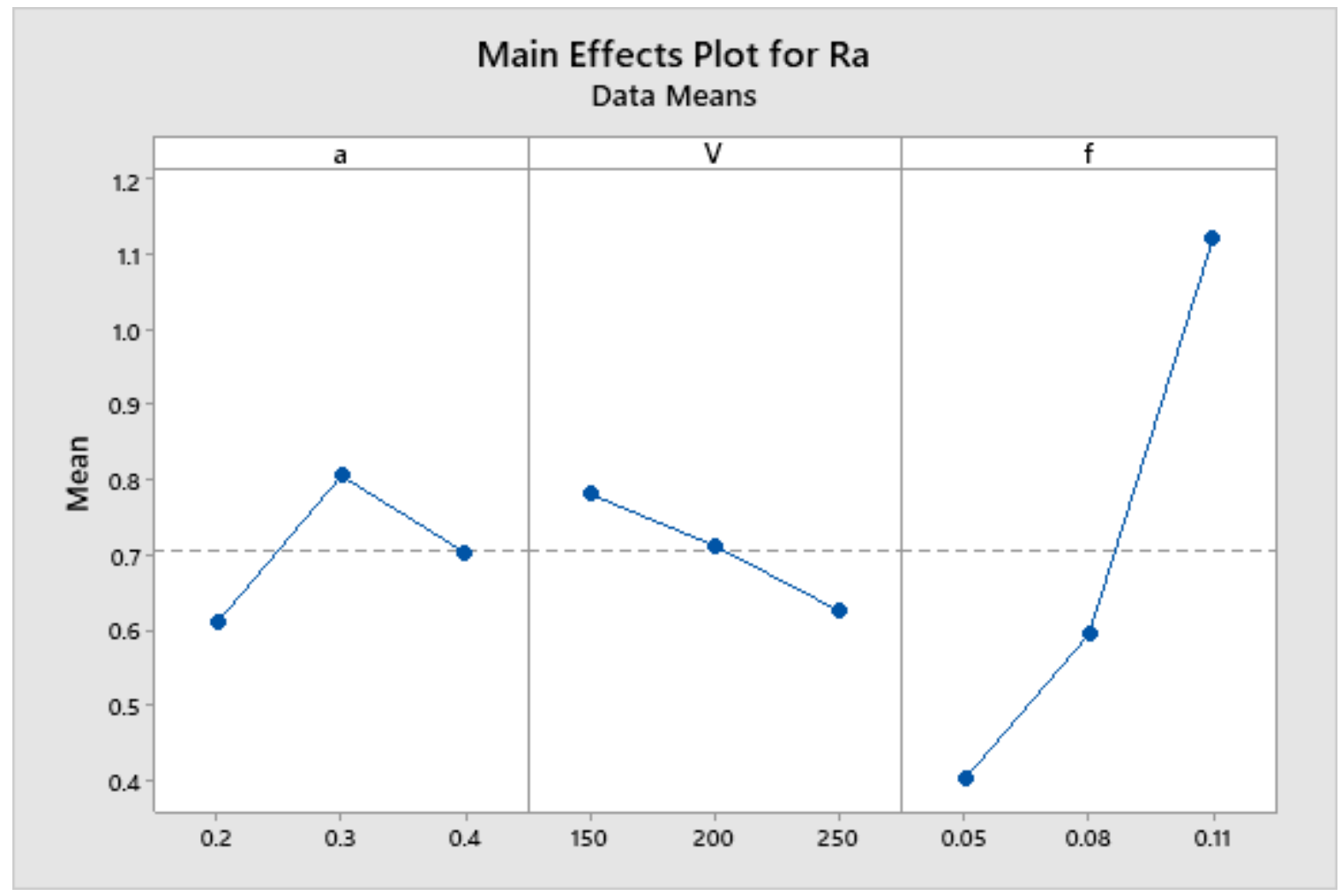

Figure 7. Main effects plot for surface roughness (carbide insert).

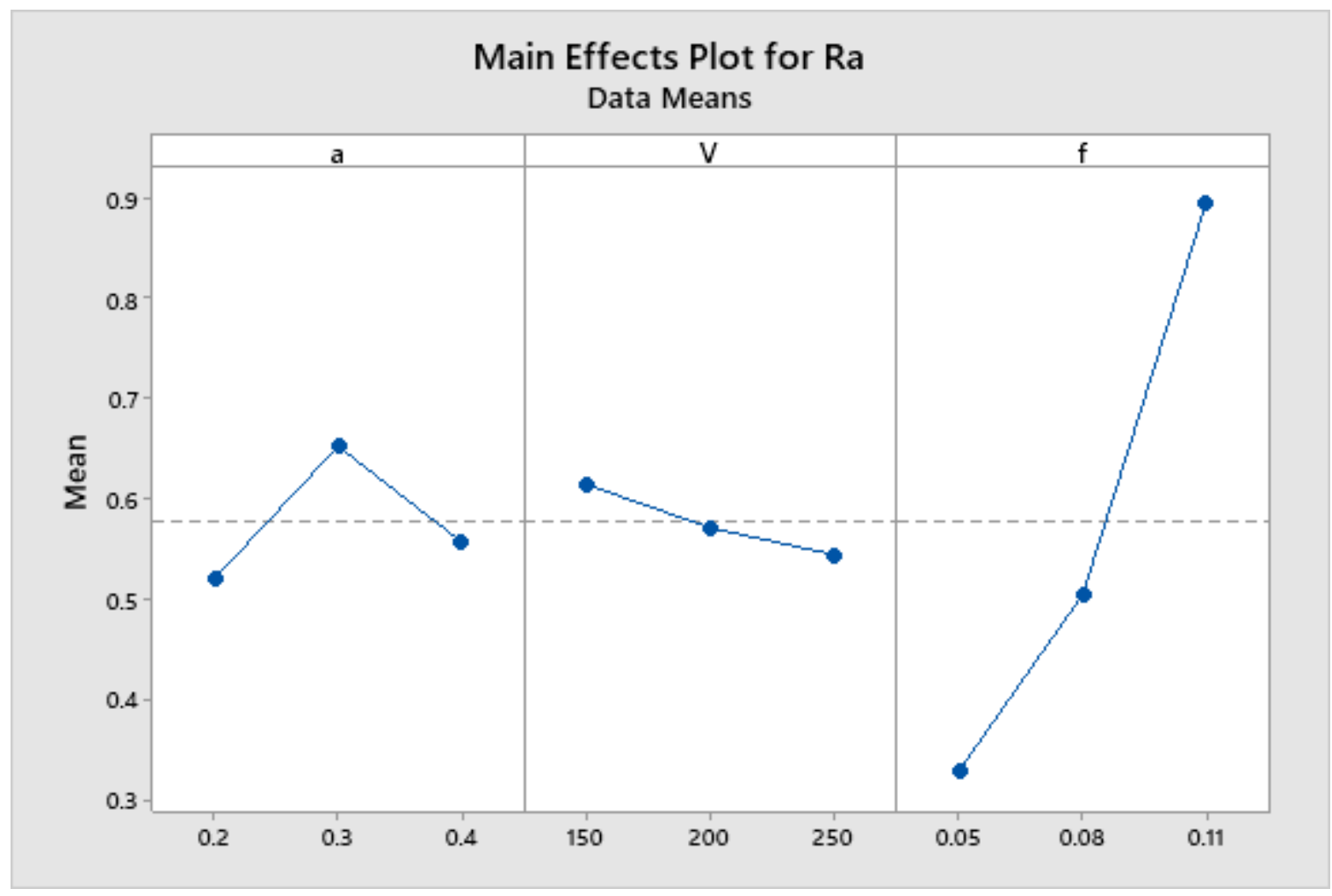

Figure 8. Main effects plot for surface roughness (ceramic insert). 


\subsection{Analysis of Variance (ANOVA)}

In this investigation, ANOVA was used to explain the statistical importance of the feed rate, the cutting speed, and the depth of cut on the surface roughness by utilizing Minitab program. The relationship of all cutting parameters was resolved through ANOVA and S/N ratios. Also, response surface methodology was utilized, regression equations were obtained, and ideal cutting parameters were resolved.

The investigational outcomes of cutting parameters were examined utilizing the analysis of variance to decide the most critical machining parameters that act on the surface roughness as given in Table 6. In this table, $\mathrm{P}$ is the significant factor, $\mathrm{D}$ the degree of freedom, $\mathrm{F}$ the variance ratio. This examination was performed for an importance level alpha of 0.05 . The input parameter impact on the response variable is important when the P-value is lower than 0.05. The first part of Table 6 presents carbide insert ANOVA results for surface roughness (Ra). It can be seen that the feed rate (f) is the main factor affecting surface roughness with an $80.57 \%$ contribution. Product $\mathrm{f}^{2}$ has also a minor impact on $(\mathrm{Ra})$ with a $5.79 \%$ contribution. The cutting speed and the depth of cut have no impressive impact on surface roughness.

Table 7. Results of ANOVA for surface roughness (carbide insert).

\begin{tabular}{crrrrrrr} 
Source & DF & Seq SS & Contribution & Adj SS & Adj MS & F-Value & P-Value \\
\hline Model & 6 & 0.926073 & $96.13 \%$ & 0.926073 & 0.154346 & 8.28 & 0.112 \\
Linear & 3 & 0.825731 & $85.71 \%$ & 0.825731 & 0.275244 & 14.77 & 0.064 \\
a & 1 & 0.013067 & $1.36 \%$ & 0.013067 & 0.013067 & 0.70 & 0.491 \\
V & 1 & 0.036504 & $3.79 \%$ & 0.036504 & 0.036504 & 1.96 & 0.297 \\
f & 1 & 0.776161 & $80.57 \%$ & 0.776161 & 0.776161 & 41.65 & 0.023 \\
Square & 3 & 0.100342 & $10.42 \%$ & 0.100342 & 0.033447 & 1.79 & 0.377 \\
a*a & 1 & 0.044402 & $4.61 \%$ & 0.044402 & 0.044402 & 2.38 & 0.263 \\
V*V & 1 & 0.000162 & $0.02 \%$ & 0.000162 & 0.000162 & 0.01 & 0.934 \\
f*f & 1 & 0.055778 & $5.79 \%$ & 0.055778 & 0.055778 & 2.99 & 0.226 \\
Error & 2 & 0.037273 & $3.87 \%$ & 0.037273 & 0.018636 & & \\
Total & 8 & 0.963346 & $100.00 \%$ & & & &
\end{tabular}

The second part of Table 6 shows that ceramic insert ANOVA results for surface roughness (Ra). It can be seen that the feed rate (f) is the main factor affecting surface roughness with an $86.56 \%$ contribution. Product $\mathrm{f}^{2}$ has also a minor impact on ( $\mathrm{Ra}$ ) with a $4.16 \%$ contribution. The cutting speed and the depth of cut have no extensive impact on surface roughness.

Table 8. Results of ANOVA for surface roughness (ceramic insert).

\begin{tabular}{crrrrrrr} 
Source & DF & Seq SS & Contribution & Adj SS & Adj MS & F-Value & P-Value \\
\hline Model & 6 & 0.541435 & $97.07 \%$ & 0.541435 & 0.090239 & 11.06 & 0.085 \\
Linear & 3 & 0.492201 & $88.25 \%$ & 0.492201 & 0.164067 & 20.10 & 0.048 \\
a & 1 & 0.001980 & $0.36 \%$ & 0.001980 & 0.001980 & 0.24 & 0.671 \\
V & 1 & 0.007420 & $1.33 \%$ & 0.007420 & 0.007420 & 0.91 & 0.441 \\
f & 1 & 0.482801 & $86.56 \%$ & 0.482801 & 0.482801 & 59.16 & 0.016 \\
Square & 3 & 0.049234 & $8.83 \%$ & 0.049234 & 0.016411 & 2.01 & 0.349 \\
a*a & 1 & 0.025916 & $4.65 \%$ & 0.025916 & 0.025916 & 3.18 & 0.217 \\
V*V & 1 & 0.000133 & $0.02 \%$ & 0.000133 & 0.000133 & 0.02 & 0.910 \\
f*f & 1 & 0.023184 & $4.16 \%$ & 0.023184 & 0.023184 & 2.84 & 0.234 \\
Error & 2 & 0.016322 & $2.93 \%$ & 0.016322 & 0.008161 & & \\
Total & 8 & 0.557756 & $100.00 \%$ & & & &
\end{tabular}




\subsection{Effects of Cutting Parameters on Surface Roughness}

The consequences of cutting parameters on the surface roughness values are seen in Table 6 . As demonstrated in Table 6, the most important cutting parameter on surface roughness is the feed rate. As the feed rate increases, surface roughness values are additionally expanded. Depth of cut and cutting speed has no critical impact on surface roughness value. Figure 9 and Figure 10 show the effects of cutting parameters on surface roughness for carbide and ceramic inserts.

\section{Surface Plots of Ra}
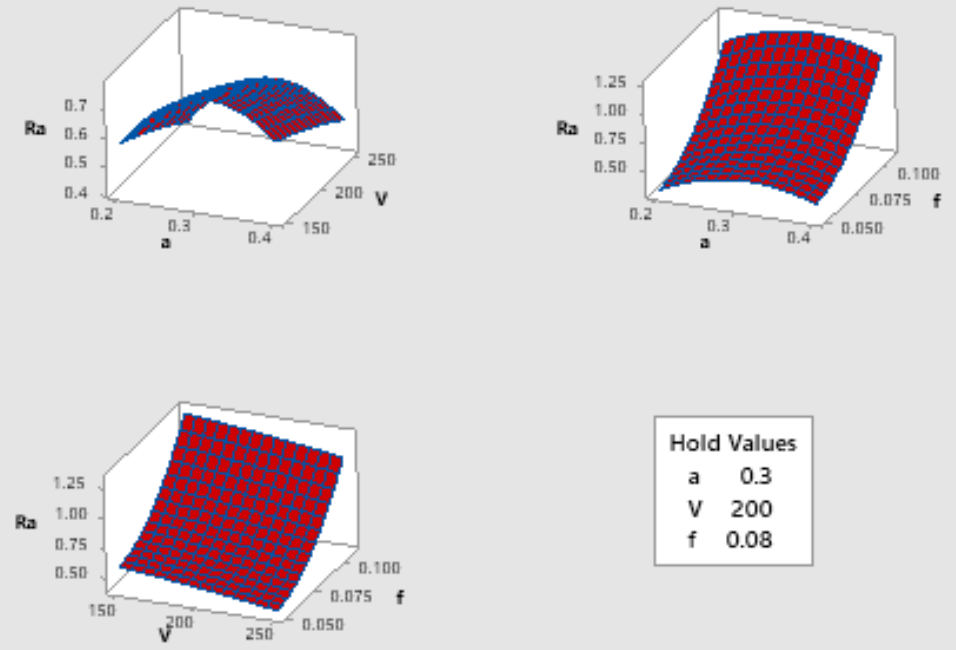

Figure 9. Effects of cutting parameters on surface roughness (carbide insert).

\section{Surface Plots of Ra}
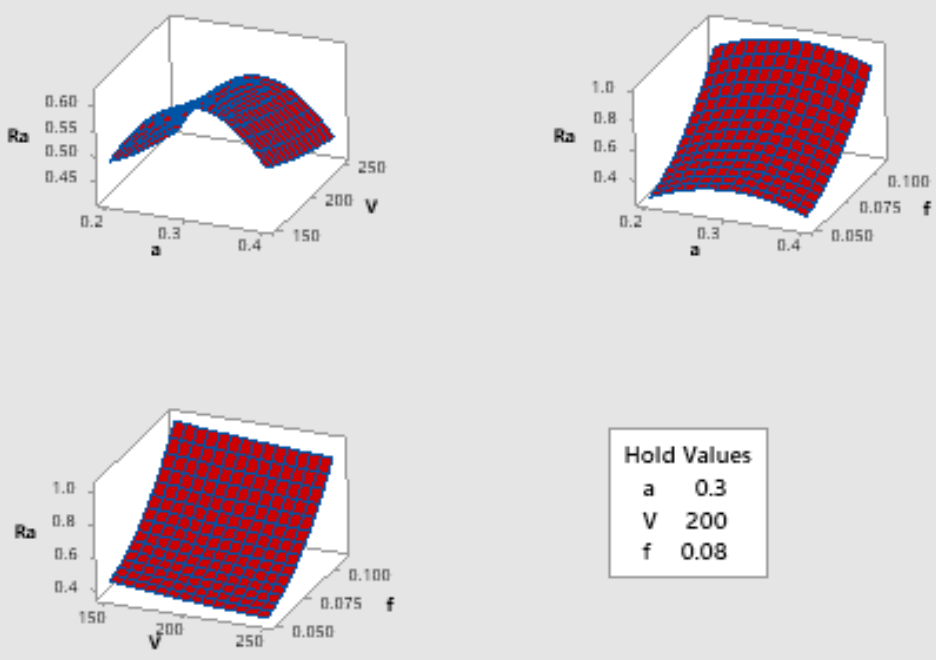

Figure 10. Effects of cutting parameters on surface roughness (ceramic insert). 


\subsection{Optimization of Cutting Parameters}

The assurance of the ideal cutting parameters in the manufacturing process which have numerous elements is especially difficult. Table 7 and Table 8 refer to the cutting parameters that compare to the smallest utilities by computing the mean of every response parameter as indicated by each input parameter.

The acquired result from ANOVA showed that feed rate is the most important parameter on surface roughness. High feed rate unfavourably influences surface quality because of the development of a continuous chip that expands the temperature in both tool and workpiece. High temperature upgrades friction among workpiece and tool; thus, the surface roughness increases. Subsequently, the best surface quality can be gotten with the combination of high cutting speed and low feed rate.

\subsection{Regression Equations}

Regression equations were introduced to discover the relation between the dependent and independent factors. Moreover, the determination coefficient $\left(\mathrm{R}^{2}\right)$ is calculated for the dependent factors to recommend the best equation.

In this investigation, regression analysis was acted to develop mathematical models utilizing input parameters including cutting speed, feed rate and depth of cut during turning of AISI 420. Investigating experimental data and developing the optimization model for surface roughness was performed utilizing Minitab programming.

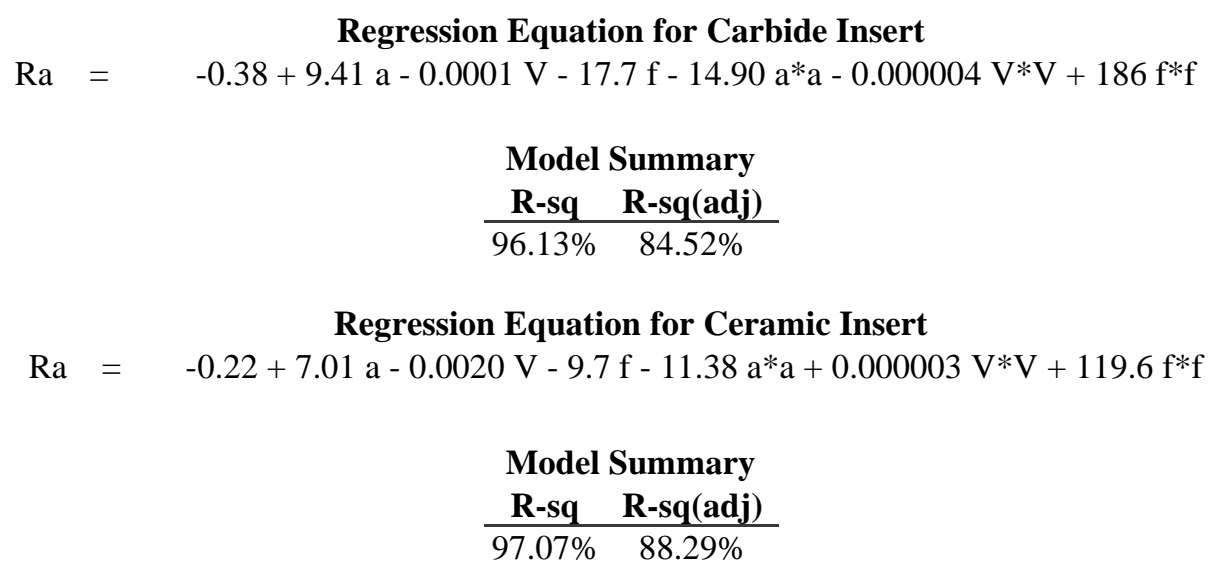

\section{Conclusion}

In this exploratory examination, the impacts of cutting parameters on response factors for two different cutting inserts were researched utilizing RSM, ANOVA, and regression equations. Response surface methodology (RSM) was utilized to acquire the relationship between the input and output variables and to characterize the ideal cutting variables. Test results were examined utilizing a statistical ANOVA method. Obtained results are presented below:

1. According to the analysis of variance, the impact of the feed rate on a surface roughness value is $80.57 \%$ in the cutting insert with a coated carbide type. In this examination, the surface roughness value was modelled with a precision of $96.13 \%$. As the feed rate expands, the surface roughness value also increases. Additionally, the impact of cutting speed and depth of cut on 
the surface roughness is insignificant. The error contribution for surface roughness value is $3.87 \%$. This implies that the experiment result for surface roughness is reliable.

2. According to the ANOVA, the impact of the feed rate on a surface roughness value is $86.56 \%$ in the cutting insert with a ceramic type. In this examination, the surface roughness value was modelled with a precision of $97.07 \%$. As the feed rate expands, the surface roughness value also increases. Additionally, the impact of cutting speed and depth of cut on the surface roughness is insignificant. The error contribution for surface roughness value is $2.93 \%$. This implies that the experiment result for surface roughness is reliable.

\section{References}

[1] Acar, E.; Camuşcu, N.; Er, A.O.; Aslan, E.: Experimental robust optimal machining of hardened AISI 420 stainless steel with A12O3 TiCN mixed ceramic tool. Proc. IMechE Vol. 225 Part B: J. Engineering Manufacture 1033-1039 (2010)

[2] Das, S.R.; Panda, A.; Dhupal, D.: Experimental investigation of surface roughness, flank wear, chip morphology and cost estimation during machining of hardened AISI 4340 steel with coated carbide insert. Mechanics of Advanced Materials and Modern Processes 3:9 (2017)

[3] Kalyon, A.; Günay, M.; Özyürek, D.: Application of grey relational analysis based on Taguchi method for optimizing machining parameters in hard turning of high chrome cast iron. Adv. Manuf. (2018)

[4] Palanisamy, D.; Devaraju, A.; Arulkirubakaran, D.; Manikandan, N.: Experimental investigation on surface integrity during machining of AISI 420 steel with tungsten carbide insert. Materials Today: Proceedings 22 (2020) 992-997 (2019)

[5] Ferreira, R.; Carou, D.; Lauro, L.H.; Davim, J.P.:Surface Roughness Investigation in the Hard Turning of Steel Using Ceramic Tools, Materials and Manufacturing Processes, 31:5, 648-652 (2016)

[6] Das, S.R.; Panda, A.; Dhupal, D.: Analysis of surface roughness in hard turning with coated ceramic inserts: Cutting parameters effects, prediction model, cutting conditions optimization and cost analysis. Ciencia e Tecnica Vitivinicola 127-154 (2017)

[7] Sahoo, A.K.; Sahoo, B.: Experimental investigations on machinability aspects in finish hard turning of AISI 4340 steel using uncoated and multilayer coated carbide inserts. Measurement 45 (2012) 2153-2165 (2012)

[8] Thamizhmanii, A.; Hasana, S.: Machinability of Hard Martensitic Stainless Steel and Hard Alloy Steel by CBN and PCBN tools by Turning Process. Proceedings of the world Congress on Engineering 2011 Vol I (2011)

[9] Zerti, A.; Yallese, M.A.; Meddour, I.; Belhadi, S.; Haddad, A.; Mabrouki, T.: Modeling and multi-objective optimization for minimizing surface roughness, cutting force, and 
power, and maximizing productivity for tempered stainless steel AISI 420 in turning operations. The International Journal of Advanced Manufacturing Technology (2018)

[10] Panda, A.; Das, S.R.; Dhupal, D.: Surface Roughness Analysis for Economical Feasibility Study of Coated Ceramic Tool in Hard Turning Operation. Process Integr Optim Sustain (2017)

[11] Manivel, D.; Gandhinathan, R.: Optimization of surface roughness and tool wear in hard turning of austempered ductile iron (grade 3) using Taguchi method. Measurement 93 (2016)

[12] Meddour, I.; Yallese, M.A.; Khettabi, R.; Elbah, M.; Boulanouar, L.: Investigation and modeling of cutting forces and surface roughness when hard turning of AISI 52100 steel with mixed ceramic tool: cutting conditions optimization. The International Journal of Advanced Manufacturing Technology 77(5-8):1387-1399 (2014)

[13] Asiltürk, İ.; Akkuş, H.: Determining the effect of cutting parameters on surface roughness in hard turning using the Taguchi method. Measurement 44 (2011) 1697-1704 (2011)

[14] Bartarya, G.; Choudhury, S.K.: Effect of Cutting Parameters on Cutting Force and Surface Roughness During Finish Hard Turning AISI 52100 Grade Steel. Procedia CIRP 1(1):651-656 (2012)

[15] Das, S.R.; Kumar, A.; Dhupal, D.: Experimental investigation on cutting force and surface roughness in machining of hardened AISI 52100 steel using cBN tool. International Journal of Machining and Machinability of Materials 15(5/6):501-521 (2016)

[16] Rashid, W.B.; Goel, S.; Davim, J.P.; Joshi, S.N.: Parametric design optimization of hard turning of AISI 4340 steel (69 HRC). The International Journal of Advanced Manufacturing Technology 82(1-4) (2015)

[17] Elbah, M.; Yallese, M.A.; Aouici, H.; Mabrouki, T.; Rigal, J.F.: Comparative assessment of wiper and conventional ceramic tools on surface roughness in hard turning AISI 4140 steel. Measurement 46 (2013) 3041-3056 (2013)

[18] Srithar, A.; Palanikumar, K.; Durgaprasad, B.: Experimental Investigation and Surface Roughness analysis on Hard Turning of AISI D2 Steel using Polycrystalline Cubic Boron Nitride (PCBN). Materials Today: Proceedings 16 (2019) 1061-1066 (2019)

[19] Zerti, A.; Yallese, M.A.; Zerti, O.; Nouioua, M.; Khettabi, R.: Prediction of machining performance using RSM and ANN models in hard turning of martensitic stainless steel AISI 420. Proc IMechE Part C: J Mechanical Engineering Science 0(0) 1-24 (2019)

[20] Agrawal, A.; Goel, S.; Rashid, W.B.; Price, M.: Prediction of surface roughness during hard turning of AISI 4340 steel (69 HRC). Applied Soft Computing 30 (2015) 279-286 (2015) 